\title{
Arterial stiffness and decline of renal function in a primary care population
}

Citation for published version (APA):

van Varik, B. J., Vossen, L. M., Rennenberg, R. J., Stoffers, H. E., Kessels, A. G., de Leeuw, P. W., \& Kroon, A. A. (2017). Arterial stiffness and decline of renal function in a primary care population.

Hypertension Research, 40(1), 73-78. https://doi.org/10.1038/hr.2016.113

Document status and date:

Published: 01/01/2017

DOI:

10.1038/hr.2016.113

Document Version:

Publisher's PDF, also known as Version of record

Document license:

Taverne

Please check the document version of this publication:

- A submitted manuscript is the version of the article upon submission and before peer-review. There can be important differences between the submitted version and the official published version of record.

People interested in the research are advised to contact the author for the final version of the publication, or visit the DOI to the publisher's website.

- The final author version and the galley proof are versions of the publication after peer review.

- The final published version features the final layout of the paper including the volume, issue and page numbers.

Link to publication

\footnotetext{
General rights rights.

- You may freely distribute the URL identifying the publication in the public portal. please follow below link for the End User Agreement:

www.umlib.nl/taverne-license

Take down policy

If you believe that this document breaches copyright please contact us at:

repository@maastrichtuniversity.nl

providing details and we will investigate your claim.
}

Copyright and moral rights for the publications made accessible in the public portal are retained by the authors and/or other copyright owners and it is a condition of accessing publications that users recognise and abide by the legal requirements associated with these

- Users may download and print one copy of any publication from the public portal for the purpose of private study or research.

- You may not further distribute the material or use it for any profit-making activity or commercial gain

If the publication is distributed under the terms of Article $25 \mathrm{fa}$ of the Dutch Copyright Act, indicated by the "Taverne" license above, 


\title{
Arterial stiffness and decline of renal function in a primary care population
}

\author{
Bernard J van Varik ${ }^{1,2}$, Liv M Vossen ${ }^{1,2}$, Roger J Rennenberg ${ }^{1}$, Henri E Stoffers ${ }^{3}$, Alfons G Kessels ${ }^{4}$, \\ Peter W de Leeuw ${ }^{1,2}$ and Abraham A Kroon ${ }^{1}$
}

Arterial stiffness is an important pathophysiological factor linking cardiovascular disease and kidney disease. Controversy exists as to whether arterial stiffness causes renal function decline, or kidney dysfunction leads to stiffening or whether the association is mutual. We aimed to investigate the longitudinal association between arterial stiffness and annual rate of renal function decline. We prospectively investigated in a primary care population whether carotid-femoral pulse wave velocity (PWV) was associated with estimated glomerular filtration rate (eGFR) and annual decline in eGFR in participants aged $\geqslant 40$ years without overt kidney disease. Baseline data on PWV and eGFR were available for 587 participants; follow-up measurements with a mean duration of 5.6 years were available for $\mathbf{2 2 2}$ patients. PWV, female gender and mean arterial pressure were independently associated with eGFR at baseline, although age confounded this association. More importantly, baseline PWV, age and eGFR were independent predictors of renal function decline. Stratification for age showed that the effect of PWV on rate of eGFR decline was amplified with advancing age. On the other hand, baseline eGFR did not determine annual change in PWV, suggesting a unidirectional association between arterial stiffness and eGFR. Arterial stiffness amplifies age-related renal function decline, suggesting that arterial stiffness plays a causal role in the development of renal damage, at least at later stages of age-related renal function decline, possibly through impaired renal autoregulation and increased arterial blood pressure pulsatility.

Hypertension Research (2017) 40, 73-78; doi:10.1038/hr.2016.113; published online 8 September 2016

Keywords: arteries; glomerular filtration rate; prospective studies; vascular stiffness

\section{INTRODUCTION}

Patients with cardiovascular diseases such as atherosclerosis and hypertension often develop renal damage that sometimes progresses to chronic kidney disease. However, even in the absence of cardiovascular disease, kidney function progressively declines with advancing age.

In both cardiovascular disease and aging, the stiffness of the arterial wall increases that leads to a rise in systolic blood pressure (SBP) together with a fall in diastolic blood pressure (DBP), causing pulse pressure (PP) to widen. ${ }^{1,2}$ The question remains of whether arterial stiffness is an independent pathophysiological mechanism in age-related renal function decline in addition to advancing age.

Studies assessing the association between arterial stiffness and renal function provided conflicting results. ${ }^{3-5}$ However, many of these studies have been performed in specific populations such as established kidney disease or renal transplant recipients, did not evaluate arterial stiffness using standard measurement techniques or have been cross-sectional in design, making it difficult to assess a cause-and-effect relationship.
Therefore, we aimed to longitudinally evaluate in a primary care population without overt kidney disease whether arterial stiffness, measured as the carotid-femoral pulse wave velocity (cfPWV), is associated with annual rate of renal function decline and whether this effect is independent of age.

\section{METHODS}

The present study was based on 587 participants of the HIPPOCRATES project who consented to vascular stiffness measurements. The project is an ongoing study designed to investigate the role of hypertension, target organ damage and cardiovascular risk in a single primary care population located in Kerkrade in the south of the Netherlands. Details of this study have been published previously. ${ }^{6}$ The present study was conducted in two phases: a baseline, cross-sectional phase and a follow-up phase that commenced at least 3 years after the baseline phase was completed. A randomly selected part of eligible participants from the baseline phase were invited for follow-up vascular measurements. Patients were eligible for follow-up measurement if they had not experienced a cardiovascular event such as myocardial infarction or stroke and were willing to undergo vascular measurements. Participants provided written informed consent. The study was conducted in accordance with the

\footnotetext{
${ }^{1}$ Department of Internal Medicine, Maastricht University Medical Centre and Cardiovascular Research Institute Maastricht (CARIM), Maastricht, The Netherlands; ${ }^{2}$ Zuyderland Medical Center, Sittard, The Netherlands; ${ }^{3}$ Department of Family Medicine, Maastricht University, Maastricht, The Netherlands and ${ }^{4}$ Department of Clinical Epidemiology and Technology Assessment Maastricht, Maastricht University Medical Centre, Maastricht, The Netherlands

Correspondence: Dr BJ van Varik, Department of Internal Medicine, Maastricht University Medical Centre, P Debyelaan 25, POB 5800, 6202 AZ Maastricht, The Netherlands. E-mail: b.vanvarik@maastrichtuniversity.nl

Received 26 March 2016; revised 1 July 2016; accepted 15 July 2016; published online 8 September 2016
} 
Declaration of Helsinki and was approved by the Maastricht Medical Ethics Committee.

\section{Clinical measurements}

Clinical baseline and follow-up visits were performed at the general practice. At baseline, we interviewed participants about smoking and alcohol consumption and obtained a complete medical and family history. We collected data on baseline cardiovascular medication use from the computerized information system of the general practice. Patients were treated by their general practitioner according to standard clinical practice. Physicians were at liberty to change medication when clinically required during the course of the study. We measured height, weight, waist and hip circumference at each study visit. Body mass index was calculated as weight divided by squared height. We measured blood pressure and heart rate three times using an aneroid sphygmomanometer after the patient had been seated for at least $10 \mathrm{~min}$. Hypertension was defined as systolic blood pressure $>140 \mathrm{~mm} \mathrm{Hg}$ and/or diastolic blood pressure $>90 \mathrm{~mm} \mathrm{Hg}$ or being on antihypertensive medication, according to the 2013 guidelines of the European Society of Hypertension. ${ }^{7}$ Mean arterial pressure (MAP) was calculated using the formula: $\mathrm{MAP}=[(2 \times \mathrm{DBP})+\mathrm{SBP}] / 3$. We obtained fasting blood samples to determine serum concentrations of creatinine, glucose, total cholesterol, low-density lipoprotein cholesterol, high-density lipoprotein cholesterol and triglycerides. Diabetes was defined as a fasting serum glucose concentration of $\geqslant 6.5 \mathrm{mmol}^{-1}$ and/or use of insulin or antidiabetic medication.

\section{Arterial stiffness measurements}

As marker for arterial stiffness we measured cfPWV, a method considered to be the gold standard marker of arterial stiffness. ${ }^{8}$ We measured PWV two times: once at baseline and once at follow-up. Measurements were performed using a Complior device (Alam Medical, Vincennes, France) that determines the transit time of the pulse wave propagation between two sensors placed on the skin over the common carotid artery and common femoral artery. ${ }^{8}$ We measured the direct distance between both sensors using a tape measure and was multiplied by 0.8 as was recommended by van Bortel et al. ${ }^{9}$ The cfPWV was then calculated by dividing the adjusted distance by the transit time. We averaged four consecutive measurements to reduce measurement variability. Before investigation, participants had been resting in a supine position for $15 \mathrm{~min}$ in a quiet room with dimmed lights. Certified operators performed all PWV measurements. In our laboratory, the reproducibility of PWV measurements is excellent and comparable to that in literature. ${ }^{10}$ The intraclass correlation coefficient for intraobserver variability was $0.93(P<0.001)$, and for interobserver variability was $0.92(P<0.001)$ Annual change in PWV was calculated as the absolute difference between PWV at follow-up and baseline, divided by the number of years of follow-up time.

\section{Creatinine measurements and estimation of glomerular filtration rate}

Until February 2007, baseline serum creatinine levels were determined using the Jaffe method on Roche diagnostic systems. Thereafter, follow-up assays were done with an enzymatic method on a Roche Modular PPE analyzer (Roche Analytics, Almere, The Netherlands). Based on internal laboratory validation measurements, in order to compare baseline (Jaffé-based) creatinine measurements to follow-up enzymatic creatinine measurements, all baseline creatinine values were corrected by the formula: corrected baseline creatinine $=$ (baseline creatinine $\times 1.06)-25 .{ }^{11}$ We estimated glomerular filtration rate (eGFR) using the CKD-EPI (Chronic Kidney Disease Epidemiology Collaboration) equation. ${ }^{12}$ Patients with a baseline eGFR of $<30 \mathrm{ml} \mathrm{min}^{-1}$ per $1.73 \mathrm{~m}^{2}$ were excluded from analysis, as were patients with primary kidney disease as manifested by a nephritic urinary sediment or nephrotic proteinuria. We calculated annual change in eGFR by subtracting baseline eGFR from the eGFR measured at the time of the follow-up vascular measurement and dividing it by the follow-up duration in years.

\section{Statistical analysis}

Statistical analyses were performed using Statistical Package for the Social Sciences (SPSS) statistical software, version 20.0 (SPSS, Chicago, IL, USA).
Data were analyzed after examination of distribution and skew using appropriate statistical tests. A $P$-value of $<0.05$ was considered statistically significant. Data are expressed as means \pm s.d., unless indicated otherwise. To compare baseline and follow-up measurements, we used paired sample Student's $t$-test for continuous data, paired sample Wilcoxon signed rank test for non-normally distributed data and the McNemar test for dichotomous data. The main outcome (annual change in eGFR) was analyzed using multivariable linear regression, correcting for confounders such as age, gender, MAP, body mass index, total cholesterol, serum glucose levels, smoking (pack years), use of different groups of antihypertensive medication and use of statins. ${ }^{13}$ We did not adjust for PP as this is also a marker of arterial stiffness. In addition to baseline values of confounders, we adjusted for annual change in PWV, annual change in blood pressure and baseline eGFR. As studies have shown that arterial stiffness may have a different effect on the rate of progression of eGFR with advancing age, we performed a sliding mean analysis to assess whether age affects the correlation between PWV and annual change in eGFR. ${ }^{3,5}$ In addition, we performed a subgroup analysis using 62 years as a cutoff value.

\section{Power calculation}

For cross-sectional analysis we calculated that with a power of $90 \%$ and $\alpha 5 \%$ the minimal detectable difference in mean eGFR was $2.5 \mathrm{ml} \mathrm{min}^{-1}$ per $1.73 \mathrm{~m}^{2}$ with the 587 participants of the baseline cohort. For follow-up measurements, to detect a minimal annual change in eGFR of $0.6 \mathrm{ml} \mathrm{min}{ }^{-1}$ per $1.73 \mathrm{~m}^{2}$ with a power of $90 \%$ and a two-sided $\alpha$ of $5 \%$, at least 154 participants would be needed.

\section{RESULTS}

\section{Cross-sectional association of baseline PWV and eGFR}

The baseline HIPPOCRATES study cohort consisted 587 participants. Table 1 shows the baseline characteristics of the studied population. In linear regression analysis cfPWV was significantly and inversely associated with eGFR. In addition to cfPWV, female gender and MAP were associated with eGFR. In a model adjusting also for age, however, cfPWV was no longer independently associated with eGFR ( $\beta-0.41$; $95 \%$ confidence interval -0.99 to $0.18 ; P=0.173$ ).

\section{Longitudinal association between baseline PWV and annual decline of eGFR}

In total, 222 participants from the baseline study cohort consented to follow-up vascular measurements (see Figure 1). This group was comparable with the one studied at baseline (Table 1). The mean duration of follow-up was 5.6 years (range 3.4-7.7 years). During that time, eGFR significantly fell by $11.6 \mathrm{ml} \mathrm{min}^{-1}$ per $1.73 \mathrm{~m}^{2}$; the average annual rate of eGFR change was $-2.0 \pm 1.9 \mathrm{ml} \mathrm{min}^{-1}$ per $1.73 \mathrm{~m}^{2}$. Mean cfPWV decreased by $0.6 \mathrm{~m} \mathrm{~s}^{-1}$ per year. Baseline cfPWV was significantly and independently associated with annual decline in eGFR in both univariable ( $\beta-0.22$; $95 \%$ confidence interval -0.33 to $-0.11 ; P=0.007)$ and multivariable adjusted regression models ( $\beta-0.18 ; 95 \%$ confidence interval -0.30 to $-0.06 ; P=0.004$; Table 2). Standardized coefficients indicated that both PWV $(\beta-0.22)$ and baseline age $(\beta-0.31)$ were strong determinants of annual change in eGFR, responsible for respectively $8 \%$ and $7 \%$ of variation in the total model (total adjusted $R^{2}=0.35$ ). There was no significant collinearity between baseline age and baseline PWV. There was no significant interaction between baseline age and baseline PWV. A three-dimensional plot of the linear regression equation representing the mutual association between baseline PWV, baseline age and annual decline in eGFR is shown in Figure 2. It demonstrates that with increasing baseline age, the rate of decline in eGFR rises. If in addition to age the baseline PWV increases, the rate of eGFR decline is even greater. To further clarify this association between age, PWV and annual decline in eGFR, we performed a sliding mean analysis to investigate whether the correlation between baseline PWV and annual 
Table 1 Baseline characteristics of the cross-sectional and follow-up study cohorts

\begin{tabular}{|c|c|c|}
\hline & $\begin{array}{l}\text { Cross-sectional } \\
\text { cohort }(\mathrm{N}=587)\end{array}$ & $\begin{array}{l}\text { Follow-up cohort } \\
\qquad(\mathrm{N}=222)\end{array}$ \\
\hline Age (years) & $62 \pm 11$ & $58 \pm 9$ \\
\hline No. of females (\%) & $304(52)$ & $111(50)$ \\
\hline Weight (kg) & $78.3 \pm 14.3$ & $78.5 \pm 14.9$ \\
\hline Body mass index $\left(\mathrm{kg} \mathrm{m}^{-2}\right)$ & $27.9 \pm 4.5$ & $27.8 \pm 4.7$ \\
\hline Smoking (pack years) & $14 \pm 19$ & $12.7 \pm 19$ \\
\hline Systolic BP (mm Hg) & $145 \pm 22$ & $143 \pm 21$ \\
\hline Diastolic BP (mm Hg) & $83 \pm 10$ & $84 \pm 10$ \\
\hline MAP (mm Hg) & $104 \pm 12$ & $103 \pm 12$ \\
\hline No. of hypertensives (\%) & $392(66.8)$ & $153(68.9)$ \\
\hline Heart rate (b.p.m.) & $65 \pm 12$ & $64 \pm 11$ \\
\hline Total cholesterol (mmol I-1) & $5.6 \pm 1.1$ & $5.5 \pm 1.1$ \\
\hline LDL cholesterol (mmol $\left.\mathrm{I}^{-1}\right)$ & $3.4 \pm 1.0$ & $3.3 \pm 0.9$ \\
\hline HDL cholesterol (mmol $\left.\mathrm{I}^{-1}\right)$ & $1.5 \pm 0.5$ & $1.5 \pm 0.4$ \\
\hline Triglycerides (mmol $\mathrm{I}^{-1}$ ) & $1.6 \pm 0.9$ & $1.5 \pm 0.9$ \\
\hline No. of patients with hyperlipidemia (\%) & $121(20.6)$ & $31(19.3)$ \\
\hline No. of patients with diabetes (\%) & $71(12.1)$ & $20(8.8)$ \\
\hline Glucose $\left(\mathrm{mmol} \mathrm{I}^{-1}\right)$ & $5.7 \pm 1.5$ & $5.6 \pm 1.4$ \\
\hline Serum creatinine $\left(\mu \mathrm{mol} \mathrm{I}^{-1}\right)$ & $54 \pm 14$ & $72 \pm 16$ \\
\hline 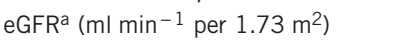 & $105 \pm 14$ & $91 \pm 14$ \\
\hline Carotid-femoral PWV $\left(\mathrm{m} \mathrm{s}^{-1}\right)$ & $9.1 \pm 2.0$ & $13.4 \pm 2.4$ \\
\hline \multicolumn{3}{|c|}{ No. of patients using antihypertensive medication } \\
\hline Diuretics (\%) & $97(16.5)$ & $31(14.4)$ \\
\hline$\beta$-Blockers (\%) & $121(20.6)$ & $40(19.4)$ \\
\hline Calcium channel blockers (\%) & $45(7.7)$ & $16(8.1)$ \\
\hline ACE inhibitors (\%) & $92(15.7)$ & $38(18.0)$ \\
\hline ARB (\%) & $30(5.1)$ & $10(4.5)$ \\
\hline Other class of antihypertensives (\%) & $4(0.7)$ & $1(0.5)$ \\
\hline
\end{tabular}

Abbreviations: ACE, angiotensin-converting enzyme; ARB, angiotensin receptor blocker; $\mathrm{BP}$, blood pressure; eGFR, estimated glomerular filtration rate; HDL, high-density lipoprotein; LDL, low-density lipoprotein; MAP, mean arterial pressure; PWV, pulse wave velocity. ${ }^{a}$ Calculated using the Chronic Kidney Disease Epidemiology Collaboration (CKD-EPI) formula.

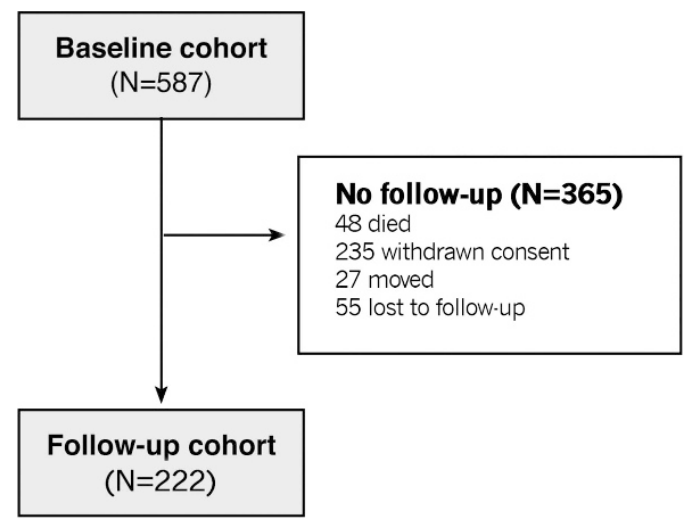

Figure 1 Flowchart of the study.

change in eGFR was stronger with advancing age. Figure 3 shows that from the age of $\sim 62$ years, the correlation between PWV and annual change in eGFR becomes stronger (see also Supplementary Figure S1). As several studies have demonstrated that chronic kidney disease is associated with development of arterial stiffness, we analyzed whether this was also the case in the present study. However, neither baseline nor annual change in eGFR were predictive of annual changes in PWV.

\section{DISCUSSION}

In the present study, we show that arterial stiffness is inversely associated with eGFR in cross-sectional analysis, but is confounded by age. Our data confirm in a primary care population previous studies that have shown a similar effect. ${ }^{3,14}$ More importantly, we demonstrated that longitudinally both baseline PWV and baseline age were strong determinants of annual rate of decline in eGFR. As eGFR was not predictive for changes in PWV, our data support the hypothesis that arterial stiffness is an important mechanism in the development of age-related renal function decline. This is a new finding as the association between vascular disease and kidney function has long been primarily attributed to arterial hypertension and changes in vascular resistance. ${ }^{15}$ Interestingly, PWV decreased over time in our data. This may reflect a treatment effect, as it has been demonstrated that several antihypertensive drugs have a lowering effect on aortic stiffness, independent of blood pressure. ${ }^{16,17}$

Several prospective follow-up studies evaluated the role of arterial stiffness and renal function in various populations with varying results, and hence the role of arterial stiffness in the pathophysiology still remains debated. ${ }^{18,19}$ For instance, in a study by Upadhyay et al. ${ }^{20}$ in 1,675 patients with mild-to-moderate kidney disease, baseline arterial stiffness was not associated with incident CKD $\left(<60 \mathrm{ml} \mathrm{min}^{-1}\right.$ per $1.73 \mathrm{~m}^{2}$ ) or eGFR. Similarly, in a study by Briet et al., ${ }^{21}$ no association was found between cfPWV and eGFR or incidence of end-stage renal disease. However, in a study by Chen et al..$^{22}$ in patients with CKD stages 3-5, brachial-ankle PWV was independently predictive of decline in eGFR, progression to dialysis and mortality. These differences in outcome could be explained by differences in the duration of follow-up, the underlying cause of kidney disease or by the possibility that other mechanisms may be more dominant at relatively late stages of CKD than in earlier stages. In the study performed by Tomiyama et al. ${ }^{23}$ in healthy Japanese employees aged 33-47 years, a higher baseline brachial-ankle PWV was significantly associated with increased decline in eGFR. A meta-analysis by Sedaghat et al. ${ }^{24}$ showed that PP and PWV were predictive of incident chronic kidney disease, defined as a eGFR of $<60 \mathrm{ml} \mathrm{min}^{-1}$. In a study among HIV-infected patients, the presence of chronic kidney disease was associated with a higher central blood pressure, greater augmentation index as well as higher PWV compared with HIV patients without CKD, supporting the association between central artery stiffness and renal damage. ${ }^{25}$

\section{Age as confounder}

As confirmed by the cross-sectional analysis of our data, age has been known to be a strong confounder of the cross-sectional association between arterial stiffness and renal function. Because of this close interrelationship, it has been proposed that age is the main determinant of eGFR. However, in this way age is used as unmodifiable risk factor, where it also can be regarded as a 'container' consisting of multiple different and specific physiological mechanisms. These include stiffening of the arteries, widening of arterial PP, endothelial dysfunction and others. ${ }^{26}$ Therefore, when studying the mechanisms that are responsible for age-related renal function decline, adjusting for age attenuates the effect of individual mechanisms occurring with (vascular) aging. This could explain why some studies failed to demonstrate an independent association.

Nevertheless, in our study age and baseline PWV remained significant predictors even after multivariable adjustment, showing that PWV contributes to rate of renal function decline, in addition to normal aging. Moreover, we found this effect mainly occurs above the age of $\sim 62$ years, suggesting that PWV seems to act as an amplifier of the age-related decline in renal function. This suggests that the renal 
microcirculation of elderly people is more vulnerable to the damaging hemodynamic effects of arterial stiffness than in younger people. This could reflect an impaired blood pressure buffering capacity of the vascular wall, caused by arterial stiffening, that occurs mainly with advancing age. Indeed, Mitchell et al..$^{2,27,28}$ demonstrated that central arterial hemodynamics significantly change from the age of $\sim 60$ years as a result of arterial stiffening and, thereby, contribute to increased blood pressure pulsatility.

\section{Mechanism of arterial stiffness-related renal damage}

Increased stiffening of the arterial vasculature reduces the pressure buffering capabilities of the vascular wall. ${ }^{2}$ This results in an increased speed of both the forward traveling pulse wave as well as in earlier

Table 2 Determinants of annual change in eGFR after follow-up $(N=222)$

\begin{tabular}{|c|c|c|c|c|}
\hline & $\beta$ & s.e. & $95 \% \mathrm{Cl}$ & P-value \\
\hline \multicolumn{5}{|l|}{ Model A (crude, $\mathrm{R}^{2}=0.07$ ) } \\
\hline Baseline carotid-femoral PWV & -0.22 & 0.06 & $-0.33 ;-0.11$ & 0.007 \\
\hline \multicolumn{5}{|l|}{ Model B $\left(\mathrm{R}^{2}=0.28\right)$} \\
\hline Baseline carotid-femoral PWV & -0.31 & 0.07 & $-0.43 ;-0.18$ & $<0.001$ \\
\hline Baseline eGFR & -0.06 & 0.01 & $-0.07 ;-0.04$ & $<0.001$ \\
\hline \multicolumn{5}{|l|}{ Model C $\left(\mathrm{R}^{2}=0.35\right)$} \\
\hline Baseline carotid-femoral PWV & -0.18 & 0.06 & $-0.30 ;-0.06$ & 0.004 \\
\hline Baseline eGFR & -0.07 & 0.01 & $-0.08 ;-0.05$ & $<0.001$ \\
\hline Baseline age & -0.07 & 0.02 & $-0.10 ;-0.03$ & $<0.001$ \\
\hline
\end{tabular}

Abbreviations: $95 \% \mathrm{Cl}, 95 \%$ confidence interval; eGFR, estimated glomerular filtration rate; PWV, pulse wave velocity.

Model A: crude model.

Model B: analysis adjusted for carotid-femoral PWV, gender, body mass index (BMI), total serum cholesterol, serum glucose levels, smoking pack years, mean arterial pressure (MAP), annual change in PWV, baseline eGFR, annual change in MAP and use of renin-angiotensin blockers (angiotensin-converting enzyme (ACE) inhibitors or angiotensin receptor blocker (ARB)).

Model C: Model B+age. pulse wave reflection that augments systolic pressure. Because DBP falls with arterial stiffening, the resulting increased central PP contributes to a highly pulsatile flow in the aorta and its branching arteries, including the renal vessels. ${ }^{2,28}$ Normally, the glomeruli and renal microcirculation are protected against blood pressure variations by autoregulation of the vascular tone in afferent and efferent arterioles. The development of hypertensive renal damage would indicate that this autoregulation is somehow disturbed. Although the precise mechanisms are not fully clear, there is evidence from animal models that sustained exposure to increased blood pressure pulsatility induces microvascular remodeling such as fibrosis that in turn blunts

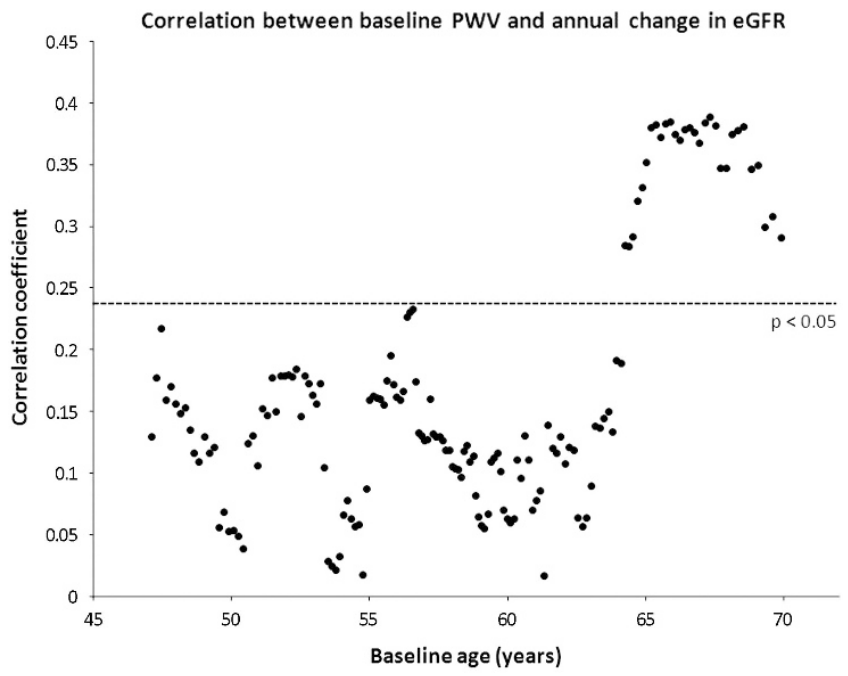

Figure 3 Correlation between baseline pulse wave velocity (PWV) and annual change in estimated glomerular filtration rate (eGFR). Plot describing the association between baseline age and Pearson's correlation between baseline PWV and annual change in eGFR. Each data point represents the mean of 50 observations. Every consequent data point differs from the previous by one observation.

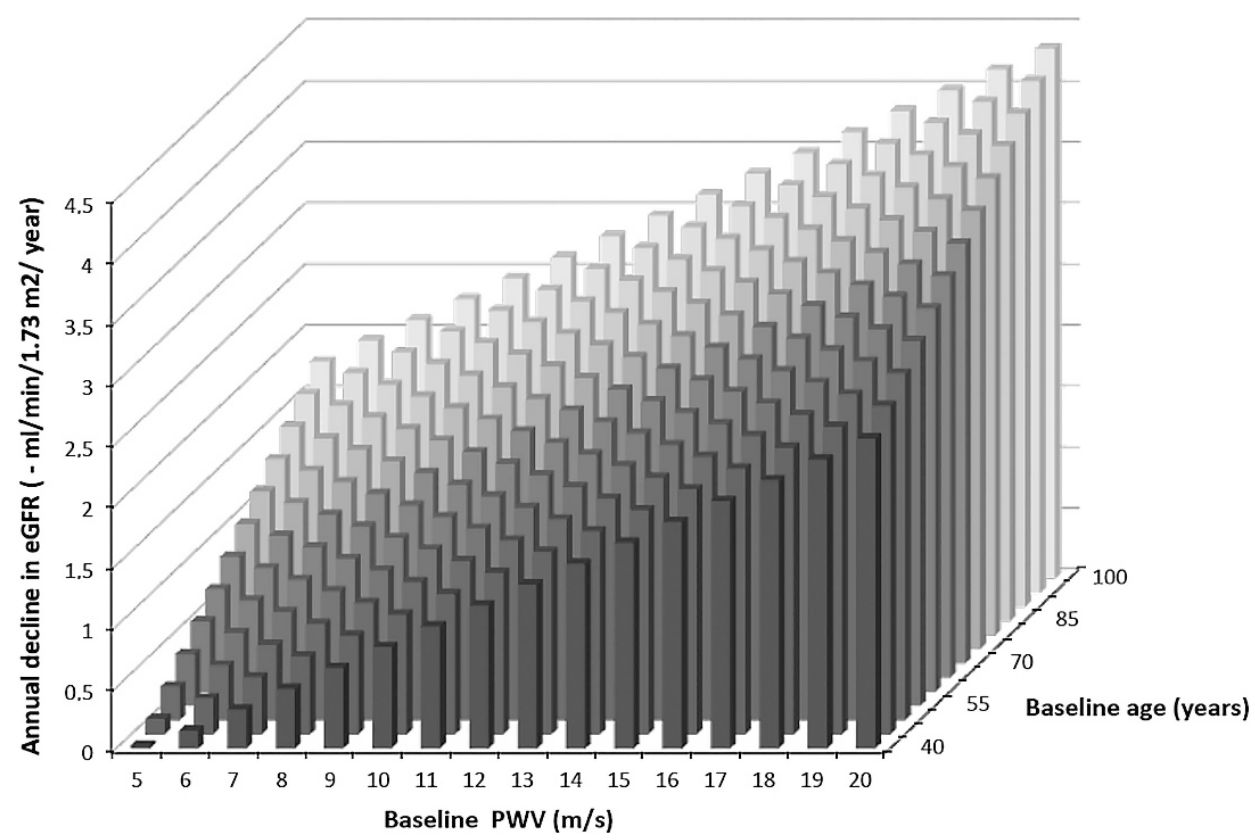

Figure 2 Age, pulse wave velocity (PWV) and annual decline in estimated glomerular filtration rate (eGFR). Three-dimensional plot of the linear regression equation between baseline PWV, baseline age and annual decline in eGFR. 
renal autoregulation. ${ }^{29}$ Indeed, in vitro the myogenic response is mainly determined by systolic blood pressure. ${ }^{30}$ In this way, the torrential pulsatile flow is transmitted to the vulnerable renal microvasculature, eventually causing either barotrauma or damage through reduced renal perfusion and oxidative stress. ${ }^{27,31}$ In support of this, Fesler et al. ${ }^{32}$ showed in human data that the amplitude of wave reflection was associated with increased glomerular pressure. In another study, they showed that baseline PP as a marker of stiffness was predictive of renal function decline in patients treated for essential hypertension, in line with our present findings. ${ }^{33}$

\section{Study limitations and strengths}

This study has some limitations. First, renal function was estimated based on creatinine measurements using the Jaffé method at baseline but using an enzymatic measurement method at follow-up. This was caused by a transition of measurement method in the clinical biochemical laboratory during the course of the study. As the Jaffé method generally overestimates creatinine values compared with enzymatic assays, we corrected the baseline Jaffé values based on internal validation measurements. This resulted in a mean correction factor of $0.78 \pm 0.1$, which corresponds to a previously reported correction factor of 0.8 , suggesting that change in eGFR may have been reliably assessed in our study. ${ }^{11}$ Moreover, with lower levels of serum creatinine and, hence, higher eGFR, the association between arterial stiffness and decline in eGFR may have been even larger without this adjustment.

Second, we did not measure urinary albumin excretion in a quantitative way. It has been demonstrated that urinary albumin excretion is a sensitive marker of renal microvascular dysfunction. ${ }^{34}$ We did obtain semi-quantitative information about urinary albumin excretion that provided an estimate of the presence of microalbuminuria. Although greater PWV levels tended to be associated with more microalbuminuria at follow-up, this association was not statistically significant and limited by the test method (urinary test-strip). Therefore, the study aimed to assess change in eGFR as this marker is commonly used in clinical practice as measure for kidney disease. Third, we unfortunately had little influence on the use of cardiovascular medication during the follow-up period. Patients were treated by their physicians according to standard medical practice, adjusting medication as required. Although we evaluated which medication participants were currently using at the follow-up visit, not all changes in medication between baseline and follow-up were adequately recorded. We analyzed whether drugs had any effect, but no conclusive information could be obtained. However, this realistically reflects a primary care situation in which patients were not limited to a specific treatment.

Our study also has several strengths. First of all, it is a prospective follow-up study in a primary care population. Therefore, the results of our study closely reflect the situation observed in common clinical practice instead of being focused on a specific patient group. Furthermore, arterial stiffness was assessed using the gold standard of noninvasive arterial stiffness measurement, the cfPWV. PWV strongly correlates with cardiovascular outcome, and reflects aortic stiffness more accurately than other markers of arterial stiffness such as PP that only partly reflect arterial compliance. ${ }^{8,35}$

\section{CONCLUSION}

We demonstrated that cfPWV amplifies age-related decline in eGFR during long-term follow-up. In addition, we found this association to be unidirectional, supporting the hypothesis that arterial stiffness is an important factor in the development of renal damage, possibly through deleterious effects of altered hemodynamics. Future research should be aimed at investigating the effects of arterial stiffness on renal microcirculation in more detail. As arterial stiffness seems to play such a key role in the development of age-related kidney function decline, treating arterial stiffness may become an increasingly important therapeutic goal. In recent years, ambulatory methods of measuring arterial stiffness have been developed that may prove useful in further investigating the interrelationship between arterial stiffness, altered hemodynamics and chronic kidney disease. ${ }^{36}$

\section{CONFLICT OF INTEREST}

The authors declare no conflict of interest.

\section{ACKNOWLEDGEMENTS}

We acknowledge Mrs M Debets and Dr F Soomers for their assistance in organizing and performing patient measurements.

1 Lee H-Y, Oh B-H. Aging and arterial stiffness. Circ J 2010; 74: 2257-2262.

2 Mitchell GF. Increased aortic stiffness: an unfavorable cardiorenal connection. Hypertension 2004; 43: 151-153.

3 Mourad JJ, Pannier B, Blacher J, Rudnichi A, Benetos A, London GM, Safar ME. Creatinine clearance, pulse wave velocity, carotid compliance and essential hypertension. Kidney Int 2001; 59: 1834-1841.

4 Smith A, Karalliedde J, De Angelis L, Goldsmith D, Viberti G. Aortic pulse wave velocity and albuminuria in patients with type 2 diabetes. J Am Soc Nephrol 2005; 16: 1069-1075.

5 Verhave JC, Fesler P, Cailar du G, Ribstein J, Safar ME, Mimran A. Elevated pulse pressure is associated with low renal function in elderly patients with isolated systolic hypertension. Hypertension 2005; 45: 586-591.

6 Plat AW, Stoffers HE, Klungel $\mathrm{OH}$, van Schayck $\mathrm{CP}$, de Leeuw PW, Soomers FL, Schiffers PM, Kester AD, Kroon AA. The contribution of six polymorphisms to cardiovascular risk in a Dutch high-risk primary care population: the HIPPOCRATES project. J Hum Hypertens 2009; 23: 659-667.

7 Task Force Members, Mancia G, Fagard R, Zanchetti A, Bohm M, Christiaens T, Cifkova R, De Backer G, Galderisi M, Grobbee DE, Jaarsma T, Kirchhof P, Kjeldsen SE, Laurent S, Manolis AJ, Nilsson PM, Ruilope LM, Schmieder RE, Sleight P, Viigimaa M, Waeber B, Zannad F, ESH Scientific Council, Redon J, Dominiczak A, Narkiewicz K, Burnier M, Viigimaa M, Caufield M, Coca A, Olsen MH, Tsioufis C, van de Borne P, ESC Committee for Practice Guidelines (CPG), Zamorano JL, Achenbach S, Baumgartner H, Bax JJ, Bueno H, Dean V, Deaton C, Erol C, Ferrari R, Hasdai D, Hoes AW, Knuuti J, Kolh P, Lancellotti P, Linhart A, Nihoyannopoulos P, Piepoli MF, Ponikowski P, Sirnes PA, Tamargo JL, Tendera M, Torbicki A, Wijns W, Windecker S, Document Reviewers, Clement DL, Gillebert TC, Tendera M, Rosei EA, Ambrosioni E, Anker SD, Bauersachs J, Hitij JB, Caulfield M, De Buyzere M, De Geest S, Derumeaux GA, Erdine S, Farsang C, Funck-Brentano C, Gerc V, Germano G, Gielen S, Haller H, Hoes AW, Jordan J, Kahan T, Komajda M, Lovic D, Mahrholdt H, Ostergren J, Parati G, Perk J, Polonia J, Popescu BA, Reiner Z, Ryden L, Sirenko Y, Stanton A, Struijker-Boudier H, Vlachopoulos C, Volpe M, Wood DA. ESH/ESC Guidelines for the management of arterial hypertension: the Task Force for the management of arterial hypertension of the European Society of Hypertension (ESH) and of the European Society of Cardiology (ESC). Eur Heart J 2013; 34: 2159-2219.

8 Laurent S, Cockcroft J, Van Bortel L, Boutouyrie P, Giannattasio C, Hayoz D, Pannier B, Vlachopoulos C, Wilkinson I, Struijker-Boudier H, on behalf of the European Network for Non-invasive Investigation of Large Arteries. Expert consensus document on arterial stiffness: methodological issues and clinical applications. Eur Heart J 2006; 27: 2588-2605.

9 Van Bortel LM, Laurent S, Boutouyrie P, Chowienczyk P, Cruickshank JK, De Backer T, Filipovsky J, Huybrechts S, Mattace-Raso FU, Protogerou AD, Schillaci G, Segers P, Vermeersch S, Weber T. Expert consensus document on the measurement of aortic stiffness in daily practice using carotid-femoral pulse wave velocity. J Hypertens 2012; 30: 445-448.

10 Pereira T, Maldonado J, Andrade I, Cardoso E, Laranjeiro M, Coutinho R, Conde J. Reproducibility of aortic pulse wave velocity as assessed with the new Complior Analyse. Blood Press Monit 2014; 19: 170-175.

11 Lamb EJ, Wood J, Stowe HJ, O'Riordan SE, Webb MC, Dalton RN. Susceptibility of glomerular filtration rate estimations to variations in creatinine methodology: a study in older patients. Ann Clin Biochem 2005; 42: 11-18.

12 Levey AS, Stevens LA, Schmid CH, Zhang YL, AF3 Castro, Feldman HI, Kusek JW, Eggers $\mathrm{P}$, Van Lente $\mathrm{F}$, Greene $\mathrm{T}$, Coresh J. A new equation to estimate glomerular filtration rate. Ann Intern Med 2009; 150: 604-612.

13 Twisk JW. Applied Longitudinal Data Analysis for Epidemiology, 4th edn., 18-26 (Cambridge University Press, UK, 2007). 
14 Kohara K, Tabara Y, Tachibana R, Nakura J, Miki T. Microalbuminuria and arterial stiffness in a general population: the Shimanami Health Promoting Program (J-SHIPP) study. Hypertens Res 2004; 27: 471-477.

15 Safar ME, Plante GE, Mimran A. Arterial stiffness, pulse pressure, and the kidney. Am J Hypertens 2015; 28: 561-569.

16 Boutouyrie P, Beaussier H, Achouba A, Laurent S. Destiffening effect of valsartan and atenolol. J Hypertens 2014; 32: 108-114.

17 Briet M, Schiffrin EL. Treatment of arterial remodeling in essential hypertension. Curr Hypertens Rep 2012; 15: 3-9.

18 Ford ML, Tomlinson LA, Chapman TPE, Rajkumar C, Holt SG. Aortic stiffness is independently associated with rate of renal function decline in chronic kidney disease stages 3 and 4. Hypertension 2010; 55: 1110-1115.

19 Gosse P, Coulon P, Papaioannou G, Litalien J, Lemetayer P. Long-term decline in renal function is linked to initial pulse pressure in the essential hypertensive. J Hypertens 2009; 27: 1303-1308.

20 Upadhyay A, Hwang SJ, Mitchell GF, Vasan RS, Vita JA, Stantchev PI, Meigs JB, Larson MG, Levy D, Benjamin EJ, Fox CS. Arterial stiffness in mild-to-moderate CKD. J Am Soc Nephrol 2009; 20: 2044-2053.

21 Briet M, Collin C, Karras A, Laurent S, Bozec E, Jacquot C, Stengel B, Houillier P, Froissart $\mathrm{M}$, Boutouyrie $\mathrm{P}$, for The Nephrotest Study Group. Arterial remodeling associates with CKD progression. J Am Soc Nephrol 2011; 22: 967-974.

22 Chen SC, Chang JM, Liu WC, Tsai YC, Tsai JC, Hsu PC, Lin TH, Lin MY, Su HM, Hwang SJ, Chen HC. Brachial-ankle pulse wave velocity and rate of renal function decline and mortality in chronic kidney disease. Clin J Am Soc Nephrol 2011; 6: 724-732.

23 Tomiyama H, Tanaka H, Hashimoto H, Matsumoto C, Odaira M, Yamada J, Yoshida M, Shiina K, Nagata M, Yamashina A. Arterial stiffness and declines in individuals with normal renal function/early chronic kidney disease. Atherosclerosis 2010; 212: 345-350.

24 Sedaghat S, Dawkins Arce FG, Verwoert GC, Hofman A, Ikram MA, Franco OH, Dehghan A, Witteman JCM, Mattace-Raso F. Association of renal function with vascular stiffness in older adults: the Rotterdam study. Age Ageing 2014; 43: 827-833.
25 Maloberti A, Dozio D, Betelli M, Bandera A, Squillace N, Gori A, Castoldi G, Stella A, Mancia G, Giannattasio C. Brachial and central blood pressure in HIV-infected subjects. Hypertens Res 2015; 38: 405-412.

26 Nilsson PM. Early vascular aging (EVA): consequences and prevention. VHRM 2008; 4: 547-552.

27 Mitchell GF. Effects of central arterial aging on the structure and function of the peripheral vasculature: implications for end-organ damage. J Appl Physiol 2008; 105: 1652-1660.

28 Mitchell GF, Parise H, Benjamin EJ, Larson MG, Keyes MJ, Vita JA, Vasan RS, Levy D. Changes in arterial stiffness and wave reflection with advancing age in healthy men and women: the Framingham Heart Study. Hypertension 2004; 43: 1239-1245.

29 Hultström M. Development of structural kidney damage in spontaneously hypertensive rats. J Hypertens 2012; 30: 1087-1091.

30 Bidani AK, Griffin KA, Williamson G, Wang X, Loutzenhiser R. Protective importance of the myogenic response in the renal circulation. Hypertension 2009; 54: 393-398.

31 Hashimoto J, Ito S. Central pulse pressure and aortic stiffness determine renal hemodynamics: pathophysiological implication for microalbuminuria in hypertension. Hypertension 2011; 58: 839-846.

32 Fesler P, Cailar GD, Ribstein J, Mimran A. Glomerular hemodynamics and arterial function in normal individuals. J Hypertens 2010; 28: 2462-2467.

33 Fesler P, Safar ME, Cailar du G, Ribstein J, Mimran A. Pulse pressure is an independent determinant of renal function decline during treatment of essential hypertension. J Hypertens 2007; 25: 1915-1920.

34 Pan CR, Roos M, Schmaderer C, Lutz J, Wang JG, Heemann U, Baumann M. Interrelationship between aortic stiffness and proteinuria in chronic kidney disease. J Hum Hypertens 2010; 24: 593-599.

35 Henskens LHG, Kroon AA van Oostenbrugge RJ, Gronenschild EHBM, Fuss-Lejeune MMJJ, Hofman PAM, Lodder J, de Leeuw PW. Increased aortic pulse wave velocity is associated with silent cerebral small-vessel disease in hypertensive patients. Hypertension 2008; 52: 1120-1126.

36 László A, Reusz G, Nemcsik J. Ambulatory arterial stiffness in chronic kidney disease: a methodological review. Hypertens Res 2016; 39: 192-198.

Supplementary Information accompanies the paper on Hypertension Research website (http://www.nature.com/hr) 